\title{
An Open-Label, Randomized, Parallel, Phase III Trial Evaluating the Efficacy and Safety of Polymeric Micelle-Formulated Paclitaxel Compared to Conventional Cremophor EL-Based Paclitaxel for Recurrent or Metastatic HER2-Negative Breast Cancer
}

\author{
In Hae Park, MD, PhD' \\ Joo Hyuk Sohn, MD, PhD² \\ Sung Bae Kim, MD, $\mathrm{PhD}^{3}$ \\ Keun Seok Lee, MD, PhD ${ }^{1}$ \\ Joo Seop Chung, MD, PhD ${ }^{4}$ \\ Soo Hyeon Lee, MD, PhD² \\ Tae You Kim, MD, PhD ${ }^{5}$ \\ Kyung Hae Jung, MD, $P h D^{3}$ \\ Eun Kyung Cho, MD, PhD \\ Yang Soo Kim, MD, PhD ${ }^{7}$ \\ Hong Suk Song, MD, PhD ${ }^{8}$ \\ Jae Hong Seo, MD, $\mathrm{Ph} \mathrm{D}^{9}$ \\ Hun Mo Ryoo, MD, PhD 10 \\ Sun Ah Lee, MD'11 \\ So Young Yoon, MD, PhD ${ }^{12}$ \\ Chul Soo Kim, MD, PhD ${ }^{13}$ \\ Yong Tai Kim, MD, PhD ${ }^{14}$ \\ Si Young Kim, MD, PhD 15 \\ Mi Ryung Jin, MS ${ }^{16}$ \\ Jungsil Ro, MD, PhD'
}

*A list author's affiliations appears at the end of the paper.

Correspondence: Jungsil Ro, MD, PhD

Center for Breast Cancer,

National Cancer Center, 323 Ilsan-ro,

Ilsandong-gu, Goyang 10408, Korea

Tel: 82-31-920-1680

Fax: 82-31-740-7269

E-mail: jungsilro@hotmail.com

Received July 5, 2016

Accepted August 26, 2016

Published Online September 12, 2016

*In Hae Park and Joo Hyuk Sohn contributed equally to this work.

${ }^{*}$ The results of this study were presented in part at the 37th San Antonio Breast Cancer Symposium 2014, San Antonio, TX

(poster presentation, program number: P3-10-04).

\section{Purpose}

Genexol-PM is a Cremophor EL-free formulation of low-molecular-weight, non-toxic, and biodegradable polymeric micelle-bound paclitaxel. We conducted a phase III study comparing the clinical efficacy and toxicity of Genexol-PM with conventional paclitaxel (Genexol).

\section{Materials and Methods}

Patients were randomly assigned (1:1) to receive Genexol-PM $260 \mathrm{mg} / \mathrm{m}^{2}$ or Genexol 175 $\mathrm{mg} / \mathrm{m}^{2}$ intravenously every 3 weeks. The primary outcome was the objective response rate (ORR).

\section{Results}

The study enrolled 212 patients, of whom 105 were allocated to receive Genexol-PM. The mean received dose intensity of Genexol-PM was $246.8 \pm 21.3 \mathrm{mg} / \mathrm{m}^{2}(95.0 \%)$, and that of Genexol was $168.3 \pm 10.6 \mathrm{mg} / \mathrm{m}^{2}$ (96.2\%). After a median follow-up of 24.5 months (range, 0.0 to 48.7 months), the ORR of Genexol-PM was 39.1\% (95\% confidence interval [Cl], 31.2 to 46.9 ) and the ORR of Genexol was $24.3 \%$ (95\% Cl, 17.5 to 31.1) (pnon-inferiority $=0.021$, $p_{\text {superiority }}=0.016$ ). The two groups did not differ significantly in overall survival ( 28.8 months for Genexol-PM vs. 23.8 months for Genexol; $p=0.52$ ) or progression-free survival (8.0 months for Genexol-PM vs. 6.7 months for Genexol; $p=0.26$ ). In both groups, the most common toxicities were neutropenia, with $68.6 \%$ occurrence in the Genexol-PM group versus $40.2 \%$ in the Genexol group ( $p<0.01)$. The incidences of peripheral neuropathy of greater than grade 2 did not differ significantly between study treatments.

\section{Conclusion}

Compared with standard paclitaxel, Genexol-PM demonstrated non-inferior and even superior clinical efficacy with a manageable safety profile in patients with metastatic breast cancer. 


\section{Introduction}

Paclitaxel, a chemotherapeutic agent that interferes with microtubule function, is among the most effective treatments for metastatic breast cancer (MBC) [1,2]. Because of its poor solubility in conventional solvent [3], paclitaxel is prepared using polyoxyl-35-castor oil (Cremophor EL; CrEL) as a solubilizer [4,5]. Unfortunately, CrEL contributes to hypersensitivity reactions in a substantial number of patients, necessitating premedication prior to paclitaxel administration [6-12].

Genexol-PM is a lyophilized polymeric micellar formulation of paclitaxel that delivers a higher paclitaxel dose to the tumor tissue with lower vehicle-related toxicities than conventional paclitaxel formulations. Unlike $\mathrm{CrEL}$, Genexol-PM is prepared using the low-molecular-weight, biodegradable amphiphilic diblock copolymer mPEG-PDLLA [methoxy(polyethylene glycol)-block-poly (D,L-lactide)] as a solubilizer [13].

Dose-limiting toxicities of Genexol-PM include neuropathy, myalgia, and neutropenia. Two phase I trials investigated the maximum tolerated dose (MTD) of Genexol-PM: one in the United States that reported an MTD of $435 \mathrm{mg} / \mathrm{m}^{2}$, and one trial in Korea that showed an MTD of $390 \mathrm{mg} / \mathrm{m}^{2}$. For safety, a dose of $300 \mathrm{mg} / \mathrm{m}^{2}$ was recommended [14]. A phase II trial used this dose of Genexol-PM in patients with $\mathrm{MBC}$ and reported a high response rate of $58.5 \%$, including complete responses (CRs) in five patients and partial responses in 19 patients [1]. This trial also showed a relatively low rate of myelosuppression even though the dose applied was higher than the conventionally used dose of CrEL-based paclitaxel [1].

In the present multicenter, open-label, randomized, phase III study, we evaluated the non-inferiority of Genexol-PM in terms of clinical efficacy compared to conventional CrELbased paclitaxel (Genexol, Samyang Biopharmaceuticals Corp.). This trial was registered with ClinicalTrials.gov, number NCT00876486.

\section{Materials and Methods}

\section{Patient population}

We performed a multicenter joint clinical trial in patients with HER2-negative advanced or metastatic invasive breast cancer at 20 institutions in Korea. Patients were eligible if they had not been treated with taxane for recurrent or metastatic disease, and had not relapsed within 1 year of receiving adjuvant paclitaxel or docetaxel treatment. Additional inclusion criteria were an Eastern Cooperative Oncology Group (ECOG) performance status of 0-2 with adequate organ function, and disease measurable using the Response Criteria in Solid Tumors (RECIST) ver. 1.0 [15]. Exclusion criteria were central nervous system metastases, current uncontrolled medical conditions that could limit the patient's ability to undergo study treatment, preexisting peripheral neuropathy above grade 1 according to the National Cancer Institute Common Toxicity Criteria, and history of allergic or hypersensitivity reactions to the study drug or any of its excipients.

All participants gave their written informed consent. The study protocol was approved by the appropriate institutional review boards and independent ethics committees, and was in compliance with Good Clinical Practice, Guidelines of the International Conference on Harmonization, and the Declaration of Helsinki.

\section{Treatment}

Patients enrolled in the study were randomly assigned (1:1) to a treatment group, with stratification by prior chemotherapy in the recurrent or metastatic setting. On the first day of each cycle, Genexol-PM (Samyang Biopharmaceuticals Corp., Seoul, Korea) was intravenously administered over 3 hours without premedication, which was repeated every 3 weeks. For safety, Genexol-PM administration began at a dose of $260 \mathrm{mg} / \mathrm{m}^{2}$, while Genexol was administered at a dose of $175 \mathrm{mg} / \mathrm{m}^{2}$. At the discretion of the physician, Genexol-PM dosage could be increased to 300 $\mathrm{mg} / \mathrm{m}^{2}$ after the first cycle. To minimize hypersensitivity, Genexol administration was preceded by premedications, including dexamethasone and H2-blockers. In the GenexolPM group, premedications were allowed in cases showing hypersensitivity or when deemed necessary by the investigator.

\section{Assessments}

Every 6 weeks, routine tumor assessments were performed based on RECIST ver. 1.0 criteria. All partial response (PR) and $\mathrm{CR}$ were confirmed with repeat imaging at least 4 weeks later. Such assessments were repeated until the time of disease progression or death.

Every cycle included laboratory testing and assessment of ECOG performance status. Adverse events were graded according to the National Cancer Institute's Common Terminology Criteria for Adverse Events (CTCAE), ver. 3.0. 


\section{Statistical analysis}

The primary objective of this study was to determine the objective response rate (ORR), defined as the fraction of patients whose maximum response was $C R$ or PR based on RECIST ver. 1.0. Secondary objectives included progressionfree survival (PFS) and overall survival (OS). This study had $80 \%$ power, with a one-sided type I error of 0.025 . The predefined non-inferiority margin was an absolute difference of $7 \%$ in the primary endpoint. After confirming non-inferiority of treatment with Genexol-PM, we tested the superiority hypothesis with the null hypothesis that ORR did not differ between the two groups.

Categorical variables were analyzed using the chi-square test, while non-parametric variables were evaluated with the Wilcoxon rank-sum test. The survival curve was analyzed using the Kaplan-Meier method, and between-group differences were evaluated using the log-rank method. Cox proportional hazard analysis was applied to identify variables that significantly influenced the objective response to the study drug. We also analyzed safety and efficacy endpoints within the per protocol population who received at least one dose of study treatments. All statistical analyses were conducted using SPSS ver. 21 (IBM Corp., Armonk, NY) while applying a two-sided significance level of $5 \%$.

\section{Results}

\section{Patient population}

This study enrolled $230 \mathrm{MBC}$ patients from December 2008 to February 2013 (CONSORT diagram) (Fig. 1), 212 of whom were included in the analyses of clinical efficacies and safety. Median patient age was 49 years (range, 28 to 72 years) in the Genexol-PM group, and 52 years (range, 25 to 78 years) in the Genexol group $(p=0.02)$ (Table 1). The two groups did not significantly differ with regards to hormone receptor status or visceral metastasis. Over $80 \%$ of patients received Genexol-PM or Genexol as first-line cytotoxic chemotherapy for advanced MBC (Table 1). The median number of previous chemotherapy treatments was one (range, 0 to 4). Patients in the Genexol-PM group underwent a median of six treatment cycles (range, 1 to 50 cycles), with a relative dose intensity of $246.8 \pm 21.3 \mathrm{mg} / \mathrm{m}^{2}(95.0 \%)$. Five patients in the Genexol-PM group received an escalated dose of 300 $\mathrm{mg} / \mathrm{m}^{2}$ starting in cycle 2. Patients in the Genexol group received a median of six treatment cycles (range, 1 to 34 cycles), with a relative dose intensity of $168.3 \pm 10.6 \mathrm{mg} / \mathrm{m}^{2}$ $(96.2 \%)$.

\section{Efficacy}

The Genexol-PM group showed an ORR of 39.1\%, with a 95\% confidence interval (CI) of 31.2 to 46.9 . The Genexol treatment group showed a lower ORR of $24.3 \%$ (95\% CI, 17.5 to 31.1), demonstrating that Genexol-PM was non-inferior

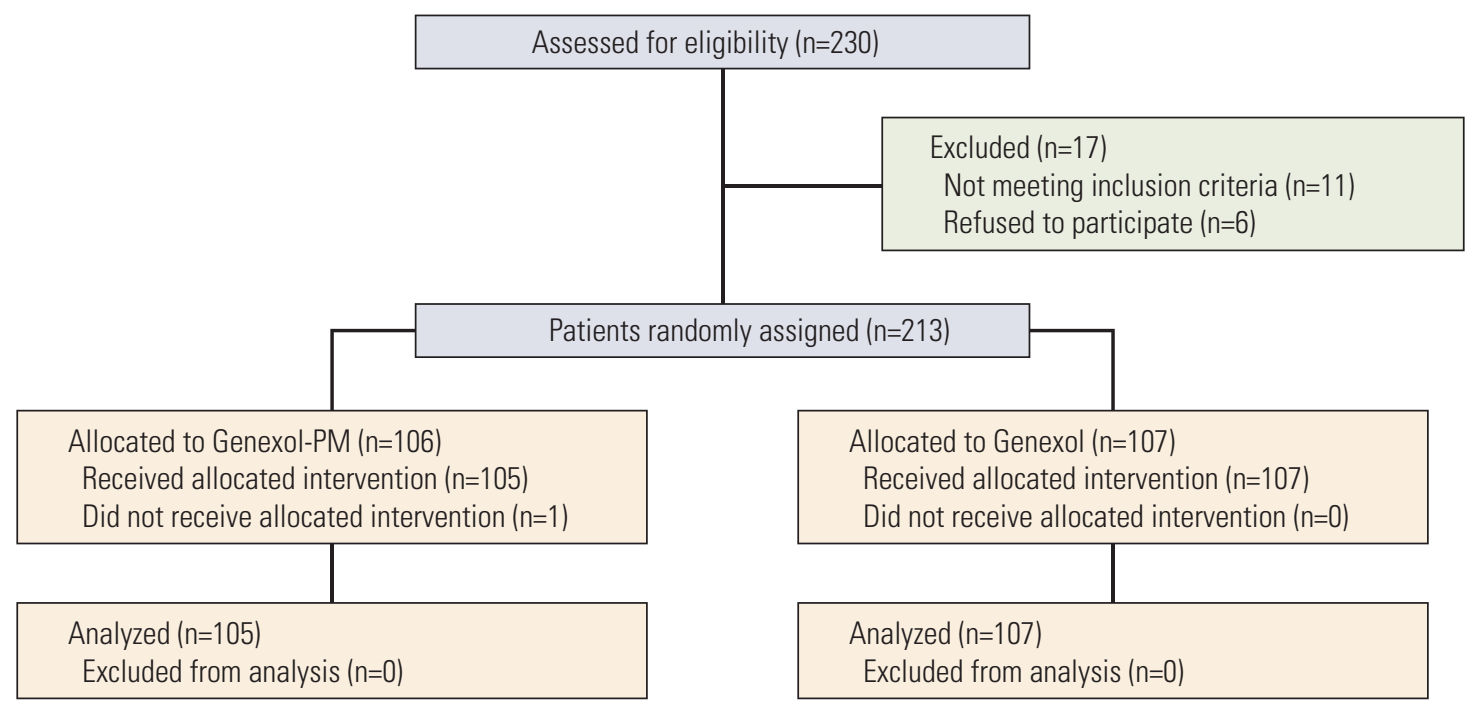

Fig. 1. CONSORT diagram. 
Table 1. Demographic and other baseline characteristics

\begin{tabular}{|c|c|c|c|}
\hline Variable & $\begin{array}{c}\text { Genexol-PM } \\
(\mathrm{n}=105)\end{array}$ & $\begin{array}{l}\text { Genexol } \\
(n=107)\end{array}$ & p-value \\
\hline Age (yr) & $49.0(28.0-72.0)$ & $52.0(25.0-78.0)$ & 0.02 \\
\hline \multicolumn{4}{|l|}{ Menstruation status } \\
\hline Premenopausal & $61(58.1)$ & $49(45.8)$ & 0.10 \\
\hline Postmenopausal & $44(41.9)$ & $58(54.2)$ & \\
\hline \multicolumn{4}{|l|}{ ECOG status } \\
\hline 0 & $47(44.8)$ & $31(29.0)$ & 0.02 \\
\hline 1 & $53(50.5)$ & $68(63.6)$ & \\
\hline 2 & $5(4.8)$ & $8(7.5)$ & \\
\hline DFI (yr) & $2.2(0.2-8.7)$ & $3.0(0.2-9.1)$ & 0.34 \\
\hline \multicolumn{4}{|l|}{ No. target lesions } \\
\hline$<3$ & $90(85.7)$ & $94(87.9)$ & 0.65 \\
\hline$\geq 3$ & $15(14.3)$ & $13(12.2)$ & \\
\hline \multicolumn{4}{|l|}{ Visceral metastasis } \\
\hline Yes & $71(67.6)$ & $65(60.8)$ & 0.30 \\
\hline No & $34(32.4)$ & $42(39.3)$ & \\
\hline \multicolumn{4}{|l|}{ ER or PgR status } \\
\hline Positive & $75(71.4)$ & $82(76.6)$ & 0.63 \\
\hline Negative & $28(26.7)$ & $24(22.4)$ & \\
\hline Unknown & $2(1.9)$ & $1(0.9)$ & \\
\hline \multicolumn{4}{|c|}{ De novo stage IV breast cancer } \\
\hline Yes & $71(67.6)$ & $74(69.2)$ & 0.81 \\
\hline No & $34(32.4)$ & $33(30.8)$ & \\
\hline \multicolumn{4}{|c|}{ Previous chemotherapya) } \\
\hline Yes & $16(15.2)$ & $14(13.1)$ & 0.70 \\
\hline No & $89(84.8)$ & $93(86.9)$ & \\
\hline
\end{tabular}

Values are presented as median (range) or number (\%). ECOG, Eastern Cooperative Oncology Group; DFI, disease-free inter-

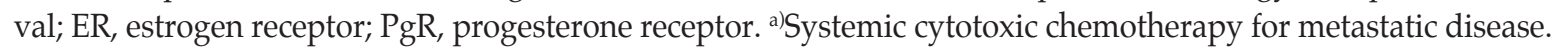

Table 2. Response rate of study treatment

\begin{tabular}{lccc} 
Variable & $\begin{array}{c}\text { Genexol-PM } \\
(\mathbf{n}=\mathbf{1 0 5})\end{array}$ & $\begin{array}{c}\text { Genexol } \\
(\mathbf{n}=\mathbf{1 0 7})\end{array}$ & p-value \\
Objective response ratea) & $41(39.1)$ & $26(24.3)$ & 0.021 \\
Complete response & 0 & 0 & \\
Partial response & $41(39.1)$ & $26(24.3)$ & \\
Stable disease & $46(43.8)$ & $56(52.3)$ & \\
Progressive disease & $7(6.7)$ & $16(15.0)$ & \\
Not evaluated & $11(10.5)$ & $9(9.4)$ & \\
\hline
\end{tabular}

Values are presented as number $(\%) .{ }^{a}$ Objective response rate $=$ complete response+partial response.

( $\left.p_{\text {non-inferiority }}=0.021\right)$ and was in fact superior to Genexol with regard to the ORR ( $p_{\text {superiority }}=0.016$ ) (Table 2 ). Clinical variables that influenced ORR included previous chemotherapy for metastatic disease (hazard ratio [HR], 2.41; 95\% CI, 0.92 to 6.35; $\mathrm{p}=0.07)$ and treatment with Genexol-PM $(\mathrm{HR}, 2.20$;
95\% CI, 1.20 to $4.06 ; \mathrm{p}=0.01$ ) (Table 3).

Subgroup analysis revealed a significantly higher response rate to Genexol-PM compared to Genexol among patients with visceral metastasis (HR, $0.35 ; 95 \% \mathrm{CI}, 0.16$ to 0.77 ; $\mathrm{p}=0.01$ ) and among patients who were chemotherapy naïve 
Table 3. Clinical variables associated with better response to treatment

\begin{tabular}{|c|c|c|c|c|}
\hline \multirow{2}{*}{ Variable } & \multicolumn{2}{|c|}{ Univariate } & \multicolumn{2}{|c|}{ Multivariate } \\
\hline & HR $(95 \%$ CI $)$ & $\overline{p \text {-value }}$ & HR $(95 \%$ CI $)$ & p-value \\
\hline Age ( $\geq 45$ yr vs. $<45$ yr) & $0.99(0.52-1.89)$ & 0.97 & & \\
\hline Genexol-PM vs. Genexol & $2.14(1.17-3.93)$ & 0.01 & $2.20(1.20-4.06)$ & 0.01 \\
\hline Premenopausal vs. postmenopausal & $0.98(0.54-1.77)$ & 0.94 & & \\
\hline Visceral involvement (yes vs. no) & $1.11(0.60-2.07)$ & 0.73 & & \\
\hline Previous treatment (no vs. yes) & $2.29(0.88-5.95)$ & 0.09 & $2.41(0.92-6.35)$ & 0.07 \\
\hline Hormone receptor (positive vs. negative) & $0.97(0.51-1.85)$ & 0.92 & & \\
\hline
\end{tabular}

HR, hazard ratio; CI, confidence interval.

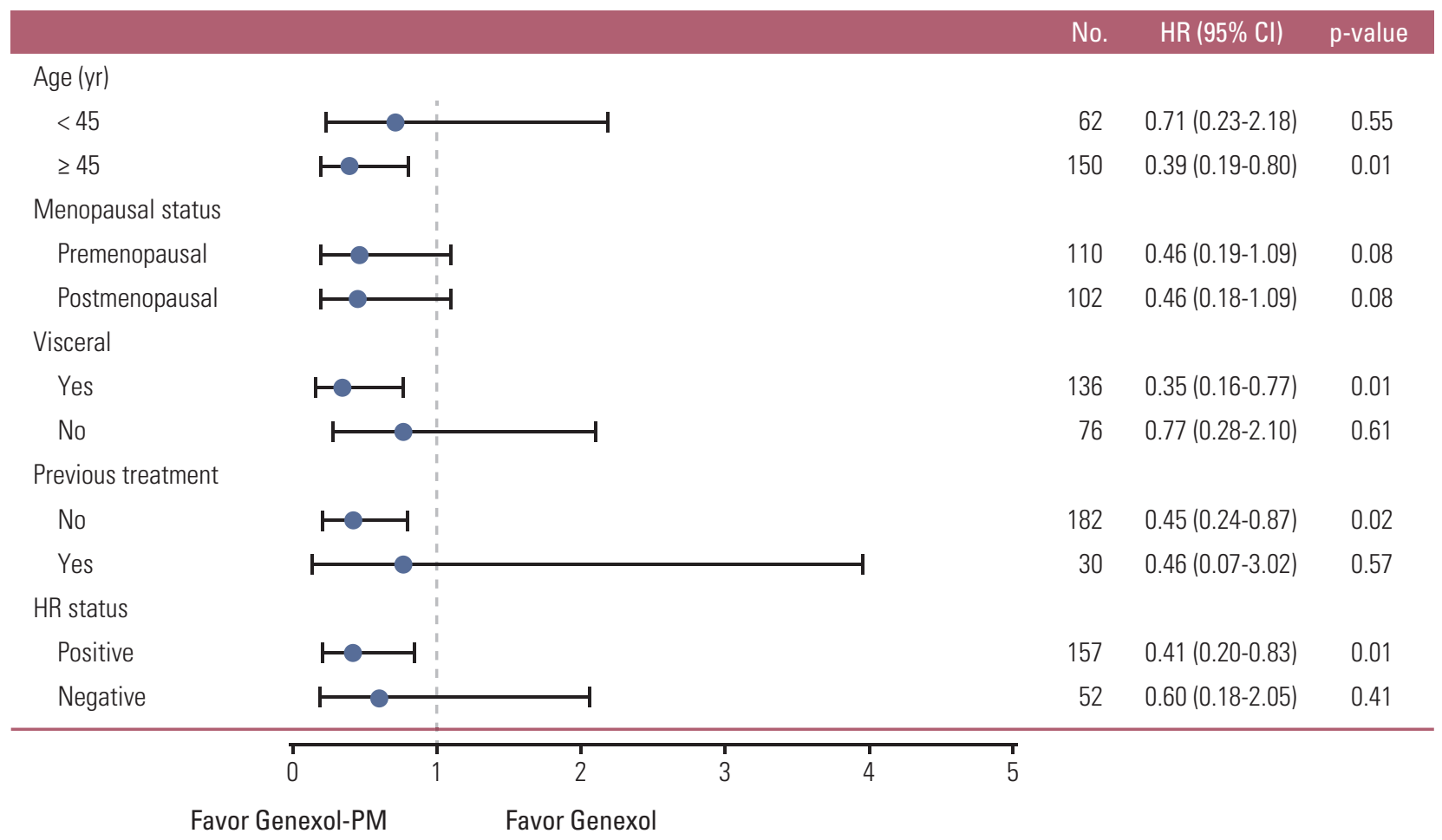

Fig. 2. Subgroup analysis of overall response rate.

for metastatic disease (HR, $0.45 ; 95 \% \mathrm{CI}, 0.24$ to $0.87 ; \mathrm{p}=0.02$ ) (Fig. 2). We also observed a greater response rate to GenexolPM among patients over 45 years of age (HR, $0.39 ; 95 \% \mathrm{CI}$, 0.19 to $0.80 ; \mathrm{p}=0.01$ ) and those with hormone receptor-positive disease (HR, $0.41 ; 95 \% \mathrm{CI}, 0.20$ to $0.83 ; \mathrm{p}=0.01$ ) (Fig. 2).

The median follow-up period was 24.5 months (range, 0.0 to 48.7 months). The median OS during this time was 28.8 months (95\% CI, 22.8 to 34.8) for the Genexol-PM group and 23.8 months (95\% CI, 18.7 to 28.9 ) for the Genexol group. The between-group difference in OS did not reach statistical significance ( $\mathrm{p}=0.52$ ) (Fig. 3A). We found a longer median PFS in the Genexol-PM group (8.0 months; 95\% CI, 6.1 to 9.9) than the Genexol group (6.7 months; 95\% CI, 5.6 to 7.8 ), but this difference did not reach statistical significance $(\mathrm{p}=0.26)$ (Fig. 3B).

\section{Safety}

According to CTCAE ver. 3.0, grade 1 or 2 toxicities comprised over $85 \%$ of the adverse events reported in both groups (Table 4). Neutropenia of grade 3 or higher was more common in the Genexol-PM group $(68.6 \%)$ than in the 
A
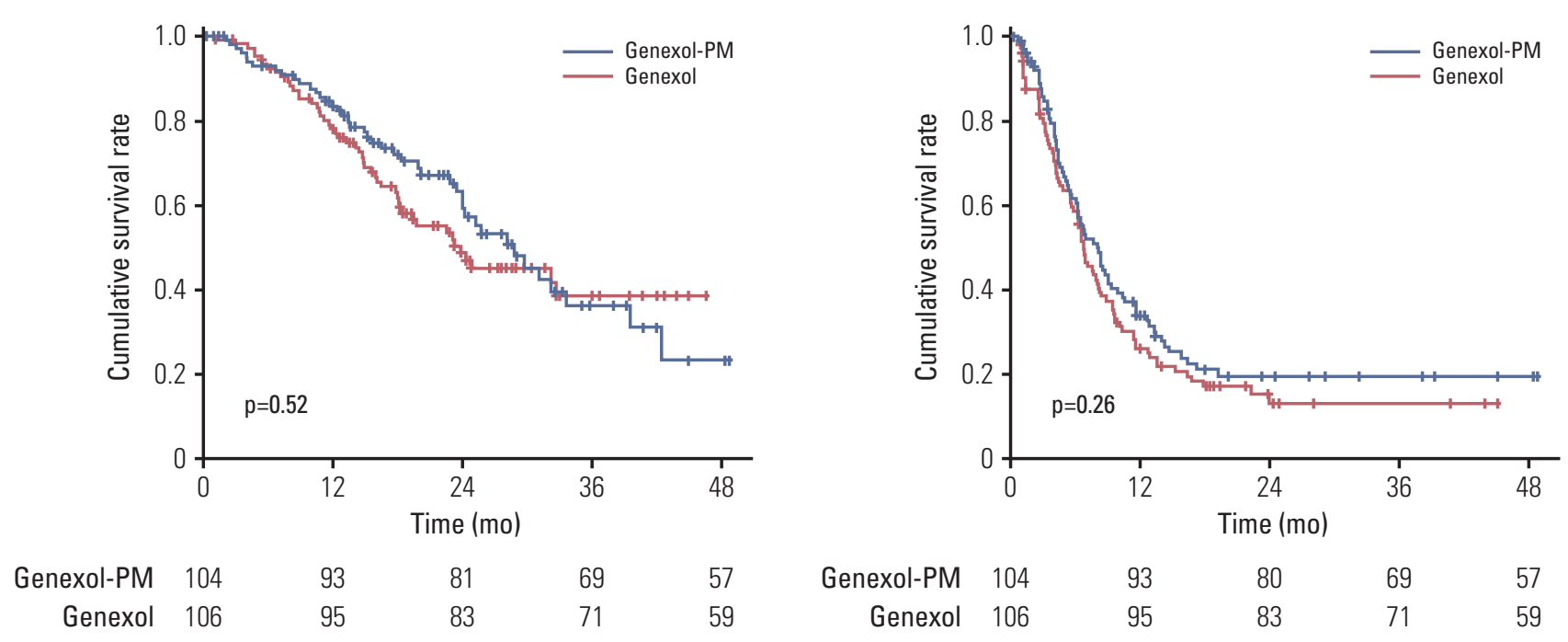

Fig. 3. Survial analysis according to treatment. (A) Overall survival. (B) Progression-free survival.

Table 4. Adverse events

\begin{tabular}{|c|c|c|c|c|c|c|}
\hline \multirow{2}{*}{ Adverse event } & \multicolumn{3}{|c|}{ Genexol-PM (n=105) } & \multicolumn{3}{|c|}{ Genexol (n=107) } \\
\hline & Grade 1 & Grade 2 & $\geq$ Grade 3 & Grade 1 & Grade 2 & $\geq$ Grade 3 \\
\hline Neutropenia & 0 & $3(2.9)$ & $72(68.6)$ & 0 & $8(7.5)$ & $43(40.2)$ \\
\hline Febrile neutropenia & 0 & $1(1.0)$ & $3(2.9)$ & 0 & 0 & $3(2.8)$ \\
\hline Myalgia & $26(24.8)$ & $28(26.7)$ & $9(8.6)$ & $32(29.9)$ & $26(24.3)$ & $8(7.5)$ \\
\hline Nausea & $25(23.8)$ & $14(13.3)$ & $3(2.9)$ & $42(39.3)$ & $6(5.6)$ & $1(0.9)$ \\
\hline Neuropathy peripheral & $13(12.4)$ & $16(15.2)$ & $8(7.6)$ & $27(25.2)$ & $14(13.1)$ & $8(7.5)$ \\
\hline Constipation & $17(16.2)$ & $22(21.0)$ & 0 & $23(21.5)$ & $17(15.9)$ & 0 \\
\hline Arthralgia & $11(10.5)$ & $12(11.4)$ & $1(1.0)$ & $9(8.4)$ & $14(13.1)$ & $3(2.8)$ \\
\hline Asthenia & $8(7.6)$ & $4(3.8)$ & $4(3.8)$ & $14(13.1)$ & $11(10.3)$ & $1(0.9)$ \\
\hline Rash & $16(15.2)$ & $11(10.5)$ & $2(1.9)$ & $12(11.2)$ & $9(8.4)$ & $4(3.8)$ \\
\hline Pruritus & $13(12.4)$ & $9(8.6)$ & 0 & $17(15.9)$ & $8(7.5)$ & 0 \\
\hline Insomnia & $13(12.4)$ & $7(6.7)$ & $1(1.0)$ & $10(9.3)$ & $7(6.5)$ & 0 \\
\hline Hypersensitivity & $5(4.8)$ & $8(7.6)$ & $3(2.9)$ & $2(1.9)$ & $1(0.9)$ & $1(0.9)$ \\
\hline
\end{tabular}

Values are presented as number $(\%)$.

Genexol group $(40.2 \%)(\mathrm{p}<0.01)$, which was expected due to the higher paclitaxel dose administered with Genexol-PM. However, the frequency of febrile neutropenia was similar between the two groups (Table 4). The incidences of $\geq$ grade 3 peripheral neuropathy and myalgia did not differ significantly according to study treatment (Table 4). Hypersensitivity to the study drugs (of any grade) was more frequent in the Genexol-PM group; therefore, the study protocol was amended to allow premedication in the Genexol-PM arm at the physician's discretion. Finally, 87 patients (82.9\%) received premedications before Genexol-PM administration. One patient dropped out of the study because of severe hypersensitivity to Genexol. All reported toxicities were manageable with conservative care. Similar numbers of patients discontinued study treatment because of adverse events in each group: 16 subjects (15.2\%) in the Genexol-PM group and 18 subjects (16.8\%) in the Genexol group. No treatmentrelated deaths occurred in either group. 


\section{Discussion}

Paclitaxel currently plays a central role in breast cancer treatment. However, the paclitaxel solubilizer CrEL contributes to severe toxicities, including hypersensitivity reactions and peripheral neuropathies [6-12]. The CALGB 9342 trial previously demonstrated that higher doses of conventional paclitaxel did not improve response rates or survival among patients with $\mathrm{MBC}$, primarily due to greater toxicities [16]. Conversely, nanoparticle albumin-bound (nab) paclitaxel at $260 \mathrm{mg} / \mathrm{m}^{2}$ resulted in much higher response rates with similar safety profiles compared to conventional paclitaxel at $175 \mathrm{mg} / \mathrm{m}^{2}$ in cases of MBC (33\% vs. $19 \%$, respectively) [17].

Several randomized trials have investigated the roles of higher paclitaxel doses for breast cancer treatment, with controversial results. The large randomized trial CALGB 40502 reported superior PFS with conventional weekly paclitaxel administration compared to weekly nab-paclitaxel in PFS as the first-line therapy for MBC (11 months vs. 9.3 months; $\mathrm{p}=0.054$ ), even though conventional paclitaxel was administered at a lower dose [18]. In contrast, in the neoadjuvant setting for early breast cancer, nab-paclitaxel, achieved significantly higher pathological CR compared with conventional paclitaxel (38\% vs. 29\%, p=0.00065) [19].

Based on the promising results of a phase II clinical trial [1], we compared the clinical efficacy of CrEL-free GenexolPM with that of conventional solvent-based paclitaxel Genexol-PM. In this context, using a different solubilizer enhanced the efficacy of drug delivery while limiting toxicities, making it possible to safely administer higher doses of paclitaxel. Consistent with previous results, we found a higher response rate for Genexol-PM than Genexol. We further found that the response rate with Genexol-PM was significantly higher among patients of more than 45 years of age, with visceral metastasis, with hormone receptor-positive disease, and in the first-line treatment setting. Although the higher response rate with Genexol-PM was not associated with improved PFS, there was a trend of longer PFS in the Genexol-PM group. It is possible that our study design targeting ORR within a relatively small population may have produced results with underpowered subgroup analysis.

Another important issue was dosing schedule. As a matter of fact, toward the end of patients accrual in the trial, weekly palictaxel or nab-paclitaxel has become recognized as a preferred schedule in view of its superiority to every three weeks schedule in CALGB 9840, NCT00274456 [20,21]. Current study demonstrated comparable clinical efficacies of Genexol-PM over standard paclitaxel in the same dosing every 3 weeks schedule, although this schedule is not widely preferred one in common practice.
Genexol-PM and conventional paclitaxel showed similar safety profiles. As expected, the Genexol-PM arm of the study showed a higher incidence of neutropenia, but similar rates of peripheral neuropathy were observed in the two groups. Hypersensitivity observed during the study period led to a requirement for premedications in the Genexol-PM group, although the majority of hypersensitivity events were easily manageable in both arms.

Considering potentially higher clinical efficacies and similar toxicity profiles, nab-paclitaxel could replace conventional paclitaxel as the first line therapy of MBC; however, its cost-effectiveness has been issued consistently. The National Institute for Health and Care Excellence (NICE) stated that using nab-paclitaxel (Abraxane) is not cost effective in view of its much higher cost and limited benefits compared to current treatment in the management of pancreatic cancer, although no such data are available in breast cancer [22]. On the other hand, Genexol-PM costs same as a generic version of the older medicine, Taxol, that it would not result in any added burden for the breast cancer patients. In this respect, Genexol-PM would be an easily accessible alternative for MBC treatment.

\section{Conclusion}

In conclusion, our present phase III study documented an improved overall response rate to Genexol-PM compared to standard Genexol treatment, with manageable toxicities with both drugs. Genexol-PM allows administration of an increased dose of paclitaxel, offering significantly improved efficacy without compromising patient safety. Further studies of Genexol-PM are warranted, particularly with the use of different schedules, including weekly doses, and in different settings in breast cancer treatment.

\section{Conflicts of Interest}

Co-author Mi Ryung Jin is an employee of Samyang Biopharmaceuticals Corporation. All remaining authors have declared that they have no conflicts of interest. 


\section{Acknowledgments}

We thank the patients who participated in this study and the study-site staff for their support. This study was sponsored by Samyang Biopharmaceuticals Corporation.

\section{Author Details}

${ }^{1}$ Center for Breast Cancer, National Cancer Center, Goyang, ${ }^{2}$ Department of Oncology, Severance Hospital, Yonsei University College of Medicine, Seoul, ${ }^{3}$ Department of Oncology, Asan Medical Center, University of Ulsan College of Medicine, Seoul, ${ }^{4}$ Division of Hematology-Oncology, Pusan
National University Hospital, Busan, ${ }^{5}$ Medical Oncology Center, Seoul National University Hospital, Seoul, ${ }^{6}$ Division of Hematology-Oncology, Gachon University Gil Medical Center, Incheon, ${ }^{7}$ Division of Hematology-Oncology, Kosin University Gospel Hospital, Busan, ${ }^{8}$ Division of HematologyOncology, Keimyung University Dongsan Medical Center, Daegu, ${ }^{9}$ Department of Hematology-Oncology, Korea University Guro Hospital, Seoul, ${ }^{10}$ Division of HematologyOncology, Daegu Catholic University Medical Center, Daegu, ${ }^{11}$ Division of Hematology-Oncology, Daegu Fatima Hospital, Daegu, ${ }^{12}$ Konkuk University Medical Center, Konkuk University School of Medicine, Seoul, ${ }^{13}$ Division of Hematology-Oncology, Inha University Hospital, Incheon, ${ }^{14}$ Division of Hematology-Oncology, National Health Insurance Service Ilsan Hospital, Goyang, ${ }^{15}$ Division of Hematology-Oncology, Kyung Hee University Medical Center, Seoul, ${ }^{16}$ Samyang Biopharmaceuticals Corporation, Seoul, Korea

\section{References}

1. Lee KS, Chung HC, Im SA, Park YH, Kim CS, Kim SB, et al. Multicenter phase II trial of Genexol-PM, a Cremophor-free, polymeric micelle formulation of paclitaxel, in patients with metastatic breast cancer. Breast Cancer Res Treat. 2008;108: 241-50.

2. Bernard-Marty C, Cardoso F, Piccart MJ. Use and abuse of taxanes in the management of metastatic breast cancer. Eur J Cancer. 2003;39:1978-89.

3. Mathew AE, Mejillano MR, Nath JP, Himes RH, Stella VJ. Synthesis and evaluation of some water-soluble prodrugs and derivatives of taxol with antitumor activity. J Med Chem. 1992;35:145-51.

4. Zhou HB, Zhu JR. Paclitaxel induces apoptosis in human gastric carcinoma cells. World J Gastroenterol. 2003;9:442-5.

5. Nonaka M, Ikeda H, Fujisawa A, Uehara M, Inokuchi T. Induction of apoptosis by paclitaxel in human oral carcinoma cells. Int J Oral Maxillofac Surg. 2006;35:649-52.

6. Rowinsky EK, Donehower RC. Paclitaxel (taxol). N Engl J Med. 1995;332:1004-14.

7. Sparreboom A, van Tellingen O, Nooijen WJ, Beijnen JH. Nonlinear pharmacokinetics of paclitaxel in mice results from the pharmaceutical vehicle Cremophor EL. Cancer Res. 1996;56: 2112-5.

8. Sparreboom A, van Zuylen L, Brouwer E, Loos WJ, de Bruijn $\mathrm{P}$, Gelderblom $\mathrm{H}$, et al. Cremophor EL-mediated alteration of paclitaxel distribution in human blood: clinical pharmacokinetic implications. Cancer Res. 1999;59:1454-7.

9. Crown J, O'Leary M. The taxanes: an update. Lancet. 2000; 355:1176-8.

10. Gelderblom H, Verweij J, Nooter K, Sparreboom A. Cremophor EL: the drawbacks and advantages of vehicle selec- tion for drug formulation. Eur J Cancer. 2001;37:1590-8.

11. van Zuylen L, Karlsson MO, Verweij J, Brouwer E, de Bruijn P, Nooter K, et al. Pharmacokinetic modeling of paclitaxel encapsulation in Cremophor EL micelles. Cancer Chemother Pharmacol. 2001;47:309-18.

12. van Zuylen L, Verweij J, Sparreboom A. Role of formulation vehicles in taxane pharmacology. Invest New Drugs. 2001;19: 125-41.

13. Kim SC, Kim DW, Shim YH, Bang JS, Oh HS, Kim SW, et al. In vivo evaluation of polymeric micellar paclitaxel formulation: toxicity and efficacy. J Control Release. 2001;72:191-202.

14. Kim TY, Kim DW, Chung JY, Shin SG, Kim SC, Heo DS, et al. Phase I and pharmacokinetic study of Genexol-PM, a cremophor-free, polymeric micelle-formulated paclitaxel, in patients with advanced malignancies. Clin Cancer Res. 2004;10:3708-16.

15. Therasse P, Arbuck SG, Eisenhauer EA, Wanders J, Kaplan RS, Rubinstein $\mathrm{L}$, et al. New guidelines to evaluate the response to treatment in solid tumors. European Organization for Research and Treatment of Cancer, National Cancer Institute of the United States, National Cancer Institute of Canada. J Natl Cancer Inst. 2000;92:205-16.

16. Winer EP, Berry DA, Woolf S, Duggan D, Kornblith A, Harris LN, et al. Failure of higher-dose paclitaxel to improve outcome in patients with metastatic breast cancer: cancer and leukemia group B trial 9342. J Clin Oncol. 2004;22:2061-8.

17. Gradishar WJ, Tjulandin S, Davidson N, Shaw H, Desai N, Bhar P, et al. Phase III trial of nanoparticle albumin-bound paclitaxel compared with polyethylated castor oil-based paclitaxel in women with breast cancer. J Clin Oncol. 2005;23: 7794-803. 
18. Rugo HS, Barry WT, Moreno-Aspitia A, Lyss AP, Cirrincione C, Leung E, et al. Randomized phase III trial of paclitaxel once per week compared with nanoparticle albumin-bound nabpaclitaxel once per week or ixabepilone with bevacizumab as first-line chemotherapy for locally recurrent or metastatic breast cancer: CALGB 40502/NCCTG N063H (Alliance). J Clin Oncol. 2015;33:2361-9.

19. Untch M, Jackisch C, Schneeweiss A, Conrad B, Aktas B, Denkert $C$, et al. Nab-paclitaxel versus solvent-based paclitaxel in neoadjuvant chemotherapy for early breast cancer (GeparSepto-GBG 69): a randomised, phase 3 trial. Lancet Oncol. 2016;17:345-56.

20. Seidman AD, Berry D, Cirrincione C, Harris L, Muss H, Marcom PK, et al. Randomized phase III trial of weekly compared with every-3-weeks paclitaxel for metastatic breast cancer, with trastuzumab for all HER-2 overexpressors and random assignment to trastuzumab or not in HER-2 nonoverexpressors: final results of Cancer and Leukemia Group B protocol 9840. J Clin Oncol. 2008;26:1642-9.

21. Gradishar W, Krasnojon D, Cheporov S, Makhson A, Manikhas G, Clawson A, et al. Randomized comparison of nab-paclitaxel weekly or every 3 weeks compared to docetaxel every 3 weeks as first-line therapy in patients (pts) with metastatic breast cancer (MBC). Eur J Cancer. 2008;6 Supple:172.

22. National Institute for Health and Care Excellence. NICE publishes final drug recommendations for the treatment of 3 separate medical conditions [Internet]. London: National Institute for Health and Care Excellence; 2015 [cited 2015 Oct 28]. Available from: https: // www.nice.org.uk/news/press-and-media / nice-publishes-final-drug-recommendations-for-the-treatment-of-3-separate-medical-conditions. 